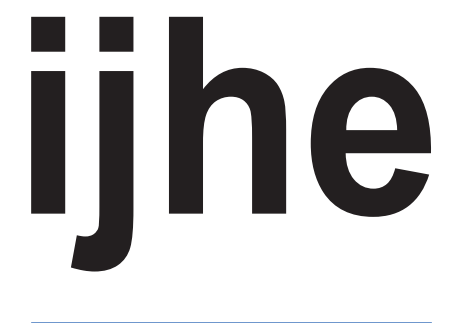

International Journal of Human Ecology

\section{The Role of Maternal Interpersonal Relation Satisfaction in the Relationship between Conflicted Teacher-Child Relationship and Negative Peer Interaction Quality in Young Children}

Kai-Sook Chung ${ }^{1}$, Mina Kim ${ }^{2}$

${ }^{1}$ Early Childhood Education, Pusan National University

${ }^{2}$ Early Childhood Education, SoongEui Women's College

\section{Abstract}

The effects of conflicted teacher-child relation on conflicted or passive peer interaction and a moderation effect of mothers' interpersonal relation satisfaction on the associations were assessed. Children from 2- to 6-year-olds (184 girls, 185 boys) mostly from middle socioeconomic-status urban community in Korea and their teachers and mothers participated. Conflicted teacher-child relation predicted conflicted peer interaction but not passive peer interaction. Children, whose relationship with teachers were conflicted, engaged in conflicted play with peers more often than children who were in less conflicted relationship with the teachers. Teachers who were in conflicted relationship with the children, perceived the children having conflicted interaction with peers more often, if mothers of the children were less satisfying in relationship with significant others, especially boys. Children, whose mothers are in less satisfying interpersonal relation with others, were more passive in peer interaction than children whose mothers are in more satisfying interpersonal relationship.

Keywords

maternal interpersonal relation satisfaction, conflicted teacher-child relationship, negative peer interaction

\section{Introduction}

Peer interaction has been described as the essence of early childhood serving as arenas for children to possess and practice a range of skills associated with various social roles. Relational characteristics have been described as eliciting changes in interaction quality among children (Hinde

Received: April 10, 2014

Revised: June 4, 2014

Accepted: June 5, 2014

Corresponding Author:

Mina Kim

Early Childhood Education, Soong-

Eui Women's College, Sopa-ro 2 gil 10,

Jung-gu, Seoul, 100-751, South Korea

Tel: +82-2-3708-9207

Fax: +82-2-3708-9102

E-mail:mkim@sewc.ac.kr
\& Stevenson-Hinde, 1976), and relationship in early life is associated to current and future social functioning of the children (Berndt \& Hoyle, 1985). Researchers in relationship studies have been interested in the correlates of successful peer relationship and have consented on that the teacher-child relationship and parent-child relationship are two major anticipants of successful peer relationship in terms of having critical impact on social functioning of children (e.g., formation and maintenance of friendship, popularity, acceptance) (see O’Conner \& McCartney, 2007; Spieker, Nelson, Petras, Jolley, \& Barnard, 2003). Children train techniques to deal with the others they encounter in the future through interactions with teachers and peers. Early childhood teachers, nevertheless, confront with challenges in managing children who are prone to demonstrate negative interaction with peers. Recent 
views in peer interaction has consistently shown that negative interaction is associated with various negative intrinsic (e.g., social competence deficit, negative affect expressiveness, antisocial trait, difficult temperament) (Kim, 2010; Rubin, Bukowski, \& Parker, 2006), extrinsic (e.g., insecure attachment, avoidance, passiveness, dominance, interpersonal incompetence) (Lamborn, Mounts, Steinberg, \& Dornbusch, 1991), and contextual factors (e.g., abusive or difficult family context, aversive social systems, inappropriate parenting) (Crockenberg \& Litman, 1990; Dishion, Patterson, Stoolmiller, \& Skinner, 1991).

Classroom environment has been considered as a context for children's social development and researchers have been interested in how the interpersonal environment is associated with children's social adjustment. The early relationships that children form with their teachers have been found to have long-lasting effects on children's emotional and social development as well as academic achievement (Pianta, 1999). Cooperative teacher-child relationship in the studies has an impact on adaptive developmental outcomes such as harmonious peer interactions in children by providing more opportunities for children to learn prosocial behavior patterns and by building children's competences in their behaviors (Birch \& Ladd, 1996a; Coie \& Dodge, 1983; Howes \& Phillipsen, 1996). Adversely, inharmonious relationships with teachers are associated with adjustment difficulties such as low level of academic performance, inactive participation, peer rejection (Birch \& Ladd, 1996a, 1997; Cassidy \& Asher, 1992; Ladd, Birch, \& Bubs, 1999).

These findings suggested that teacher-child relationship and peer interaction may be congeneric in terms of that children's behavioral trait or behavioral orientation plays a role as "constant stimulus (see Miller, 1993)" for children to react to the behavioral stimulus in the interaction context with similar pattern across different relationship domains. A child's general behavioral pattern yields similar outcomes in both peer-child and teacherchild relationship contexts. In this regard, it is anticipated that the child can maintain stability in relationship and interaction across contexts and time. Empirical evidence supports the link between an inharmonious interpersonal behavioral pattern and difficulties in peer relationship (see Coie, Dodge, \& Kupersmidt, 1990), and a recent study (Kim, 2010) reported that behavioral trait is one of the most influential factors in prediction of interaction quality among preschool children above and beyond individual demographic and socio-emotional attributes (i.e., affect expressiveness) as well as context-determined (i.e., different depending on context) behavioral factors (i.e., dominance, friendship). Further, a child's gender has been found having impact on determining the quality of the teacher-child relationship and peer interaction (Baker, 2006, Birch, 2001; Ewing \& Tayler, 2009). Girls were found having more appropriate school attitudes as well as being more cooperative and independent in classroom participation whereas boys were more frequently engaged in conflicted interaction with peers.

Research derived from ecological systems theory has explored the impact of a child's outer systems regarding a child's development and suggested not only immediate and direct impact from microsystem (i.e., family, school, peers, and neighbors), but also indirect impact from interconnections between microsystems (i.e., mother and father, parents and teachers, parents and teachers, and so on) (see Bronfenbrenner, 1979). Family members build their own characteristics, and elicit personal emotional pathology via various aspect of intrafamilial interaction and mothers' emotional status may have indirect impact (i.e., interpersonal relationship satisfaction) as well as direct impact (i.e., parenting) on their children's psychology. Parents, especially mothers, function as major influence promoting peer acceptance or peer rejection (see Hwang \& Moon, 2010; Putallaz \& Heflin, 1990), and maternal psychological characteristics influences children's behavior (Choi, 1995). Parents in high level of anxiety tended to inconsistently respond to their children's needs, and their children displayed aggressive behavior more frequently (see Choi, 1995; Davies \& Cummings, 1994). Children learn social behaviors from their mothers, and the most significant personnel in early lives have invaluable contribution on children's social interaction (Macdonald \& Parke, 1984). Mothers' social competence, such as relationship skills and abilities, seem to have impact on children's capacity of building and maintaining social relationship with peers via parentchild interaction (e.g., parenting). (Kim \& Lee, 2011). Considering these, it is assumed that mothers with high level of relationship satisfaction may treat their children in a positive way such as showing competence in relationship management, and displaying positive affect (i.e., happiness, and satisfaction) more often. Conversely, mothers with low level of relationship satisfaction 
may interact with their children in a negative way through showing incompetence in relationship maintenance, and displaying negative affect (i.e., enervation, disappointment, and frustration).

A plethora number of studies have dedicated efforts in figuring out the major factors on a child's social functioning and agreed on that parent-child relationship is one of the critical predictors of a child's social adjustment (see Cook, 2001). The findings address a question, what drives parents to have specific pattern of interaction with their children. Studies indicate that mothers who feel they are isolated and have less support from their outer system tend to show incompetence in parenting or to build aversive relationship through coercive methods of control in childrearing (Cook, 1994; Cook, Kenny, \& Goldstein, 1991). Poor social skills in mothers linked to low level of relationship satisfaction were connected to low level of self-efficacy and competence in their parental roles (see Strand \& Wahler, 1996). Further, the nature of the association between children's relationships with parents and their relationships with peers has been explored by developmental psychologists, and empirical evidences indicate that the poor quality of parenting is related to a variety of child adjustment difficulties (e.g., defiance, involvement with antisocial peers, interpersonal incompetence, and poor school achievement) (Crockenberg \& Litman, 1990; Dishion et al., 1991; Lamborn et al., 1991).

Accordingly, the assumption that maternal interpersonal relation satisfaction is linked to undesirable children's social outcomes (e.g., conflicted engagement with peers and teacher) (George \& Main, 1979) through poor quality of parent-child interaction (e.g., violent or inconsistent childrearing attitude) (Wahler \& Dumas, 1986) has been elicited. Conversely, it is assumed that mothers who satisfy in their interpersonal relationship with significant others such as spouse, friends, neighbors, in-law parents as well as their own parents are more effective in childrearing, thus yielding desirable child outcomes in peer interaction. Given the importance of maternal perception on their interpersonal relationship in childrearing, interpersonal relation satisfaction of mothers, however, has received little attention from developmental psychologists compared to studies in intrafamilial relation (i.e., parent-child, mother-father). An implication from the findings is that the maternal relation satisfaction may act as a buffer in the connection between conflicted teacher-child relationship and problematic peer interaction (i.e., moderating the connection).

Despite of the consensus on the contribution of two major influence from significant adult figures in early childhood interaction with peers (i.e., parent-child and teacher-child relationships), researchers emphasized the correlates of peer interaction in a single domain of relationship. In addition, considering the potential mechanism (i.e., moderating effect) of maternal interpersonal relation satisfaction, it is meaningful to examine any change in the relation between a child's relationship with teacher on the child's peer interaction as function of maternal satisfaction level in interpersonal relationship. Therefore, the primary goal of this study was to examine the relation between conflicted teacher-child relation and negative peer interaction (i.e., conflicted or passive) and the potential moderation effects of mothers' interpersonal relation satisfaction on the relationship between conflicted teacher-child relation and negative peer interaction were assessed. Research questions derived from the literature review were as follows:

(1) How much does conflicted teacher-child relationship predict negative peer interaction (i.e., conflicted and passive)?

(2) Does the prediction of negative peer interaction (i.e., conflicted and passive) by conflicted teacher-child relationship differ at the level of maternal interpersonal relation satisfaction?

The hypothetical model describing associations and directions of effect among all the variables based on the literature review is shown in Figure 1.

\section{Method}

\section{Recruitment of Participants}

Consent forms and a letter of invitation were sent to teachers and mothers of seventeen early childhood education and care

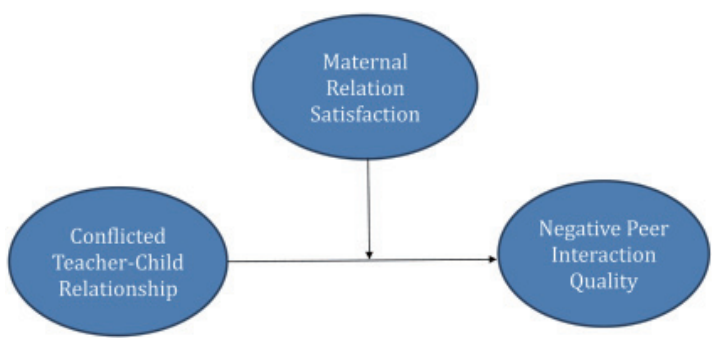

Figure 1. Hypothetical Model Describing Associations among Variables. 
Table 1. Sample Characteristics

\begin{tabular}{|c|c|c|c|c|c|}
\hline Characteristics & $N(\%)$ & $M$ & $S D$ & Min & $\operatorname{Max}$ \\
\hline Children & & 56.96 & 11.30 & 29 & 83 \\
\hline \multicolumn{6}{|l|}{ Age (month) } \\
\hline \multicolumn{6}{|l|}{ Gender } \\
\hline Girl & $184(49.7)$ & & & & \\
\hline Teacher & $61(100)$ & 61.15 & 50.67 & 9 & 279 \\
\hline \multicolumn{6}{|l|}{ Teaching Career (month) } \\
\hline \multicolumn{6}{|l|}{ Mother } \\
\hline \multicolumn{6}{|l|}{ Education } \\
\hline Graduate & $41(11.1)$ & & & & \\
\hline College Graduate & $201(54.5)$ & & & & \\
\hline High School & $41(11.1)$ & & & & \\
\hline Middle School & $2(.5)$ & & & & \\
\hline
\end{tabular}

centers in southeastern area of Korea. Mothers as well as teachers were well informed about the project by teachers and center directors, and they were asked to read and rate the given scale tool as well as to sign an informed consent form agreeing to their child's participation in the study. Mothers completed interpersonal relation satisfaction scales as well as demographic information for the child and family, such as age, gender, and SES indicators (i.e., occupation, income, education). Teachers provided information about teacher-child relationship and peer interaction of children in the classroom using prepared rating scales.

Three hundred sixty nine pairs of children and mothers participated and they were predominantly from middle class. Children included $50.1 \%$ boys and ranged 29- to 83-months of age (Table 1). Participating 61 teachers had average 5 years of teaching career (9- to 279- months of teaching). Most of participating mothers had higher education (11\% graduate, $23 \%$ undergraduate, $55 \%$ college graduate).

\section{Measures and Procedures}

\section{Conflicted Teacher-Child Relationship}

Conflicted teacher-child relationship was assessed using one subscale of the Student-Teacher Relationship Scale (STRS; Pianta, 2001; revised by Lee, 2001), which is a teacher-rating measure inquiring teachers' perceptions of relationship with children. The conflicted subscale of the STRS included 12 items such as "This child easily becomes angry with me" and "This child is sneaky or manipulative with me.” All items used a 5-point Likert scale: “definitely does not apply (1)", "does not apply (2)", "may or may not apply (3)", "may apply (4)", and "definitely applies (5)." Cronbach's alpha reliability coefficient of conflicted teacher-child relationship variable for our sample was .95 .

\section{Negative Peer Interactions}

Negative peer interactions (i.e., conflicted and passive peer interaction) were assessed using the Penn Peer Interactive Play Scale (PIPPS; Fantuzzo, Sutton-Smith, Coolahan, Manz, Canning, \& Debnam, 1995), which was designed for teachers and parents to report on children's behavior within the context of peer play in classroom. Two subscales of PIPPS were included in this study. Play Disruption and Play Disconnection. Play disruption includes 13 items relating to aggressive, antisocial play behavior that hinders ongoing peer interactions. Play Disconnection factor refers to non-participation in play, such as being withdrawn, hovering outside the play group and rejecting invitations to play (8 items). Cronbach's alphas for the two subscales (i.e., conflicted and passive peer interaction) for our sample were .88 and .88 . 
Table 2. Descriptive Data of Conflicted Teacher-Child Relation, Negative Peer Interaction and Maternal Interpersonal Relation Satisfaction

\begin{tabular}{|c|c|c|c|c|c|}
\hline Variables & Gender & $N$ & $M$ & $S D$ & $t$ \\
\hline \multirow[t]{2}{*}{ Conflicted Teacher-Child Relationship } & Girl & 184 & 2.03 & .90 & $3.05 * *$ \\
\hline & Boy & 185 & 2.34 & 1.08 & \\
\hline \multicolumn{6}{|l|}{ Negative Peer Interaction } \\
\hline \multirow[t]{2}{*}{ Conflicted } & Girl & 184 & 1.83 & .47 & $2.24 *$ \\
\hline & Boy & 185 & 1.94 & .49 & \\
\hline \multirow[t]{2}{*}{ Passive } & Girl & 184 & 1.69 & .52 & .19 \\
\hline & Boy & 185 & 1.70 & .55 & \\
\hline \multirow[t]{2}{*}{ Maternal Interpersonal Relation Satisfaction } & Girl & 184 & 3.63 & .55 & -.10 \\
\hline & Boy & 185 & 3.63 & .52 & \\
\hline
\end{tabular}

$* p<.05, * * p<.01$

\section{Maternal Interpersonal Relation Satisfaction}

Maternal interpersonal relation satisfaction scale was developed supplementing the relationship satisfaction scale (Yoon \& Kim, 2012). Participants reported on their relationship satisfaction by completing the 7-item of the scale regarding their current and past interpersonal relationship (i.e., relationships with spouse, in-law parents, classroom teacher and center director of the child, other parents in the classroom, friends, neighbors, and their own teachers from elementary through high school or college). All items used a 5-point Likert scale: "very little satisfied (1)", "a little satisfied (2)", "moderately satisfied (3)", "a little satisfied (4)", and "very much satisfied (5)." The alpha coefficient for the current sample was .71.

\section{Data Analysis}

Descriptive analyses, t-tests, ANOVAs, and regression analyses were conducted to test basic information, the degree of predictability of conflicted children-child relationship on negative peer interactions and teachers' ratings of their relationship with children. In order to predict the power of independent variables and changes in dependent variables by effect of another variable, hierarchical multiple regressions were employed, as they are useful to disclose the effect size of independent variables by adding new variables (Leech, Barrett, \& Morgan, 2008). Prior to multiple regression analysis, multicollinearity was checked to test whether the independent variable (i.e., conflicted teacher-child relationship) is highly correlated (VIF > 3) to moderator variable (i.e., maternal interpersonal relation satisfaction) and the analysis showed no multicollinearity $(\mathrm{VIF}=1.00)$.
Hierarchical regression analyses were conducted to examine how conflicted teacher-child relationship predicted a child's conflicted peer interaction. The second series of hierarchical regression analyses were performed to test whether maternal interpersonal relation satisfaction moderates the prediction of conflicted teacher-child relationship on negative peer interaction variables, using conflicted teacher-child relation as predictor in the first step, and maternal interpersonal relation satisfaction as predictor in the second step. At the final step, an interaction term (conflicted teacher-child relationship x maternal interpersonal relation satisfaction) was entered. All the regression analyses were performed in a full sample and within each separate gender groups in order to test gender difference in predictions and changes in predictions as hypothesized.

\section{Results}

\section{Primary Analyses}

Children $(N=369)$ showed moderate levels of conflicted teacherchild relationship on a 5-point scale $(M=2.19, S D=1.00)$. On a scale of 1 to 4 , the full sample of children showed relatively low levels of negative peer interaction for conflicted $(M=1.88, S D=.48)$ and for passive $(M=1.69, S D=.53)$. To test whether there were significant group mean differences in independent and dependent variables by gender of children, independent t-tests were performed. The results of t-tests revealed that there were significant gender difference in conflicted teacher-child relationship and conflicted peer interaction whereas no significant gender difference in passive peer interaction 
Table 3. Correlations Among Conflicted Teacher-Child Relationship, Negative Peer Interactions, and Maternal Interpersonal Relation Satisfaction

\begin{tabular}{lcccc}
\hline & $\mathbf{1}$ & $\mathbf{2}$ & $\mathbf{3}$ & $\mathbf{4}$ \\
\hline 1. Conflicted Teacher-Child Relationship & & $.20 * *$ & .08 & $.25 * *$ \\
2. Conflicted Peer Interaction & $.16 *$ & & $.45 * * *$ & -.04 \\
3. Passive Peer Interaction & .07 & $.51 * * *$ & -.14 \\
4. Maternal Interpersonal Relation Satisfaction & .07 & $-.17 *$ & $-.17 *$ & \\
\hline
\end{tabular}

Note. Above the diagonal is for boys and the below is for girls.

$* p<.05, * * p<.01, * * * p<.001$

Table 4. Regression Summaries on Conflicted Peer Interaction using Conflicted Teacher-Child Relation with Interaction Term of Maternal Interpersonal Relation Satisfaction

\begin{tabular}{|c|c|c|c|c|c|c|c|c|c|c|c|c|c|c|c|}
\hline & \multicolumn{5}{|c|}{ Total } & \multicolumn{5}{|c|}{ Girls } & \multicolumn{5}{|c|}{ Boys } \\
\hline & $B$ & $S E B$ & $\beta$ & $\begin{array}{c}R^{2} \\
\left(\Delta R^{2}\right)\end{array}$ & $\begin{array}{c}B \\
\text { final step }\end{array}$ & B & $\begin{array}{c}S E \\
B\end{array}$ & $\beta$ & $\begin{array}{c}R^{2} \\
\left(\Delta R^{2}\right)\end{array}$ & $\begin{array}{c}B \\
\text { final step }\end{array}$ & $B$ & $S E B$ & $\beta$ & $\begin{array}{c}R^{2} \\
\left(\Delta R^{2}\right)\end{array}$ & $\begin{array}{c}B \\
\text { final step }\end{array}$ \\
\hline Step 1: & & & & $.04 * * *$ & & & & & $.03 *$ & & & & & $.04 * *$ & \\
\hline $\begin{array}{l}\text { Conflicted } \\
\text { Teacher-Child } \\
\text { Relation(CTCR) }\end{array}$ & .20 & .05 & $.20 * * *$ & & $.32 * * *$ & .17 & .08 & $.16 *$ & & $.28 * *$ & .19 & .07 & $.20 * *$ & & $.32 * * *$ \\
\hline Step 2: & & & & $.06 * * *$ & & & & & $.06 * *$ & & & & & $.05 *$ & \\
\hline $\begin{array}{l}\text { Maternal Interpersonal } \\
\text { RelationSatisfaction(MRS) }\end{array}$ & -.14 & .05 & $-.14 * *$ & $(.02 * *)$ & $-.13 *$ & -.18 & .07 & $-.19 *$ & $(.03 *)$ & $-.20 * *$ & -.10 & .08 & -.10 & $(.01)$ & -.05 \\
\hline Step 3: & & & & $.12 * * *$ & & & & & $.11 * * *$ & & & & & $.14 * * *$ & \\
\hline CTCR $x$ MRS & & & & $(.06 * * *)$ & $-.25 * * *$ & & & & $(.05 * *)$ & $-.25 * *$ & & & & $(.09 * * *)$ & $-.26 * * *$ \\
\hline
\end{tabular}

$* p<.05, * * p<.01, * * * p<.001$

and maternal interpersonal relation satisfaction (see Table 2). Therefore, further analyses were performed in separate gender group of the sample in addition to full data.

Conflicted peer interaction showed positive, significant relationships with conflicted teacher-child relationship in both boys and girls (see Table 3). Two negative peer interaction variables were highly correlated whereas passive peer interaction is not significantly associated with conflicted teacher-child relationship as expected. Maternal interpersonal relation satisfaction showed positive association with conflicted teacher-child relationship in boys and negative associations with negative peer interaction in girls unexpectedly.

\section{Prediction of Negative Peer Interaction \\ Conflicted Peer Interaction}

The result with full sample yielded that the main effects of conflicted teacher-child relationship was found to be positive and significant. The results of regression with two different gender groups of children (i.e., boys and girls) resembled the results with full sample. The magnitude and significance of prediction of conflicted teacher-child relation in boy and girl samples were similar to the full sample.

\section{Moderation effect of maternal interpersonal relation satisfaction}

Follow-up analyses to calculate the simple intercept and slope for significant interactions tested possible moderation effects. Conflicted teacher-child relationship was entered as main effect predictor variable in the first step, and maternal interpersonal relation satisfaction as moderator variable in the second step, followed by interaction term between conflicted teacher-child relationship and maternal interpersonal relation satisfaction in the third step (see Table 4). The main effects of conflicted teacherchild relationship remained significant after maternal interpersonal relation satisfaction was entered as moderator. Interestingly, maternal interpersonal relation satisfaction independently predicted conflicted peer interaction in negative direction, and there was significant interaction effect with conflicted teacherchild relation as well. This indicates that the children who were in conflicted relation with teachers, were observed being more engaged in conflicted interaction with peers by teachers if their mothers had less satisfying relationships with significant others. 
Table 5. Regression Summaries on Passive Peer Interaction using Conflicted Teacher-Child Relation with Interaction Term of Maternal Relation Satisfaction

\begin{tabular}{|c|c|c|c|c|c|c|c|c|c|c|c|c|c|c|c|}
\hline & \multicolumn{5}{|c|}{ Total } & \multicolumn{5}{|c|}{ Girls } & \multicolumn{5}{|c|}{ Boys } \\
\hline & $B$ & $S E B$ & $\beta$ & $\begin{array}{c}\mathrm{R} 2 \\
\left(\Delta R^{2}\right) \\
\end{array}$ & $\begin{array}{c}B \\
\text { final step }\end{array}$ & $B$ & $S E B$ & $\beta$ & $\begin{array}{c}R^{2} \\
\left(\Delta R^{2}\right) \\
\end{array}$ & $\begin{array}{c}B \\
\text { final step }\end{array}$ & $B$ & $S E B$ & $\beta$ & $\begin{array}{c}R^{2} \\
\left(\Delta R^{2}\right)\end{array}$ & $\begin{array}{c}B \\
\text { final step }\end{array}$ \\
\hline Step 1: & & & & .01 & & & & & .01 & & & & & .01 & \\
\hline $\begin{array}{l}\text { Conflicted } \\
\text { Teacher-Child } \\
\text { Relation(CTCR) }\end{array}$ & .08 & .05 & .08 & & $.19 * *$ & .08 & .08 & .07 & & .16 & .08 & .07 & .08 & & $.21 * *$ \\
\hline Step 2: & & & & $.03 * *$ & & & & & $.04 *$ & & & & & $.03 *$ & \\
\hline $\begin{array}{l}\text { Maternal Interpersonal } \\
\text { RelationSatisfaction(MRS) }\end{array}$ & -.17 & .05 & $-.17 * *$ & $(.03 * *)$ & $-.16 * *$ & -.17 & .07 & $-.17 *$ & $(.03 *)$ &,$- 18 *$ & -.18 & .08 & $-.17 *$ & $(.03 *)$ & -.14 \\
\hline Step 3: & & & & $.08 * * *$ & & & & & $.06 * *$ & & & & & $.10 * * *$ & \\
\hline CTCR x MRS & & & & $(.05 * * *)$ & $-.21 * * *$ & & & & $(.03 *)$ & $-.19 *$ & & & & $(.07 * * *)$ & $-.23 * * *$ \\
\hline
\end{tabular}

$* p<.05, * * p<.01, * * * p<.001$

Follow-up analysis to calculate the simple intercept and slope for the significant interaction provided significant support for the interaction effect $(B=.32, t=7.16, p=.000$ for low maternal interpersonal relation satisfaction; $B=.07, t=.64, p=.524$ for high maternal interpersonal relation satisfaction).

Conflicted teacher-child relationship accounted for $4 \%$ of variance in conflicted peer interaction of children, and the addition of interaction term (i.e., conflicted teacher-child relationship $\mathrm{x}$ maternal interpersonal relation satisfaction) expanded the predictability. Thus the full set of predictors explained $12 \%$ of total variance with the full sample.

The results of regression with two different gender groups of children (i.e., boys and girls) resembled the results with full sample. The magnitude and significance of prediction of conflicted teacherchild relation in boy and girl samples were similar to full sample except the independent impact of moderator variable in boys was not significant. Maternal interpersonal relation satisfaction in association with conflicted teacher-child relationship explained additional $5 \%$ of the variance in conflicted peer interaction for girl sample and additional 9\% for boy sample. More specifically, both boys and girls who were in conflicted relation with teachers, were observed being more engaged in conflicted interaction with peers by teachers if their mothers were experiencing less satisfying interpersonal relationship. The interaction effects were detected in follow-up analysis in girl $(B=.28, t=6.26, p=.000$ for low maternal interpersonal relation satisfaction; $B=.03, t=.27, p=.785$ for high maternal interpersonal relation satisfaction) and boy sample ( $B=.32$, $t=7.16, p=.000$ for low maternal interpersonal relation satisfaction;
$B=.06, t=.55, p=.585$ for high maternal interpersonal relation satisfaction).

\section{Passive Peer Interaction}

The main effects of conflicted teacher-child relationship in full sample were found to be significantly positive as expected.

Moderation effect of maternal interpersonal relation satisfaction The main effect remained significant after maternal interpersonal relation satisfaction was entered as another predictor. However, maternal interpersonal relation satisfaction independently and indirectly predicted children's passive peer interaction in an association with conflicted teacher-child relationship variable, which changed the direction of prediction slope to negative. Follow-up analysis tested the assumption that the children who were in conflicted relation with teachers, were observed showing passive peer interaction more often if their mothers reported lower level of interpersonal relation satisfaction. The simple intercept and slope for the significant interaction provided significant support for the interaction effect $(B=.19, t=4.25, p=.000$ for low maternal interpersonal relation satisfaction; $B=.02, t=.18, p=.855$ for high maternal interpersonal relation satisfaction).

Although conflicted teacher-child relationship did not directly contribute in explanation of variance of passive peer interaction, the full set of predictors explained $8 \%$ of total variance in passive peer interaction with full sample and the addition of interaction term (i. e., conflicted teacher-child relationship x maternal interpersonal relation satisfaction) significantly expanded the predictability.

Table 5 reports that regression results with both boy and girl 
groups were similar to the results with the full sample in terms of the magnitude of prediction of conflicted teacher-child relation. There was no significant independent prediction by conflicted teacher-child relationship on passive peer interaction in both boy and girl samples, nevertheless, maternal interpersonal relation satisfaction increased predictability of passive peer interaction both independently and in an association with conflicted teacherchild relationship. Specifically, maternal interpersonal relation satisfaction added 3\% more in girls and 7\% more in boys in addition to its independent prediction of variance in the second step (i.e., $3 \%$ for each gender group) explaining $6 \%$ and $10 \%$ of total variance in passive peer interaction in girls and boys, respectively. More specifically, girls and boys who were in conflicted relations with teachers, were observed being passive in peer interaction more often if their mothers were in lower level of satisfaction with their interpersonal relationships. Follow-up analysis detected the interaction effects in girls $(B=.16, t=3.58, p=.000$ for low maternal interpersonal relation satisfaction; $B=-.03, t=.27, p=.785$ for high maternal interpersonal relation satisfaction) and boys $(B=.21$, $t=4.70, p=.000$ for low maternal interpersonal relation satisfaction; $B=-.02, t=-.18, p=.855$ for high maternal interpersonal relation satisfaction).

Overall, there was significant conflicted teacher-child relationship effect in prediction of conflicted peer interaction, however, not in prediction of passive peer interaction. Maternal relation satisfaction, however, played two different roles in explaining the variance in both conflicted and passive peer interactions as independent predictor and as moderator: The lower maternal interpersonal relation satisfaction, the higher association between conflicted teacher-child relationship and negative peer interactions.

\section{Discussion}

Contemporary views on relationship and interaction research suggests a homogeneity between same valences of relationship and interaction, and that is supported by empirical evidences in developmental psychology probing the positive connections between harmonious interpersonal relationship and desirable social outcomes in children, and between conflicted interpersonal relationship and negative adjustment problems among young children. In addition, regarding associations between relationship and interactions, the attributes and correlates of relationship and interaction have seldom been investigated in more than one domain of relationship. Given the importance of relations among relationships with teacher, parent, and peer on a child's social adjustment, not much research has investigated the relations together. This study, therefore, aimed to test the premise of the positive association between conflicted teacher-child relationship and negative peer interaction, and to examine whether the association differs depending on mothers' interpersonal relation satisfaction.

Positive association between conflicted teacher-child relationship and conflicted peer interaction

Although there was no significant correlation between conflicted teacher-child relationship and passive peer interaction, the premise of positive association between same valence of relationship and interaction (i.e., negative relationship and negative interaction) was supported, and that is in consistent with previous research (Birch \& Ladd, 1996a, 1997; Cassidy \& Asher, 1992; Ladd, Birch, \& Bubs, 1999). The finding may support Miller (1993)'s suggestion of behavioral trait as constant stimulus that draws similar pattern across different interpersonal context (i.e., teacher-child to peerchild).

Moderating role of maternal interpersonal relation satisfaction in prediction of conflicted teacher-child relationship on negative peer interaction

For conflicted peer interaction, children who were perceived as being in conflicted relation with teachers, were observed engaging in conflicted interaction with peers more often if their mothers were less satisfied in relationship with others, compared to children with mothers with higher satisfaction in their interpersonal relationship. This phenomenon was more obvious for boys, interestingly. It may be related to the well-known gender difference that girls are less often engaged in conflicted peer interaction and are less often in conflicted relationship with teachers compared to boys (see Baker, 2006; Birch, 2001). Also, this finding implicates that mothers' negative perception on their own relation with others influence children's interpersonal functioning by offering children to observe 
and learn negative responses to frustrating or stressful relational situation. Further, the magnitude of impact may be larger in boys since boys have more aggressive behavioral tendency (see Kim, 2010). Although girls are more relationship-oriented (i.e., easily effected by psycho-emotional condition of others) in interpersonal interaction as Sheldon (1992) suggested, they are less frequently engaged in conflicted interaction with peers, the magnitude of impact of mothers' psychological wellbeing (e.g., relation satisfaction) on their negative peer interaction may be found small. ). In order to better understand this phenomenon, it would be helpful to examine whether boys still display more aggressiveness in interaction than girls if mothers' interpersonal relation satisfaction level is same.

Children in conflicted teacher-child relationship were not engaged in passive peer interaction significantly more often than children in less conflicted teacher-child relationship. Nevertheless, the modest magnitude of correlation coefficient led us to test regression model and found significant interaction effect of conflicted teacher-child relationship on passive peer interaction in association with maternal interpersonal relation satisfaction. Considering interaction effect as well as independent effect of maternal interpersonal relation satisfaction in prediction of passive peer interaction, it is suggested to treat maternal interpersonal relation satisfaction as separate predictor for passive peer interaction rather than moderator of the connection.

Children who were perceived being in conflicted relation with teachers, were observed showing passive peer interaction more often if their mothers reported lower interpersonal relation satisfaction level. This finding may support the idea that low level of maternal interpersonal relation satisfaction has impact on children's negative adjustment outcomes (i.e., conflicted interaction with peers and teachers) through poor quality of parent-child interaction (Crockenberg \& Litman, 1990; Lamborn et al., 1991; Strand \& Wahler, 1996; Wahler \& Dumas, 1986). It is suggested for future studies to include more pathways such as parenting styles or self-efficacy as caregiver in the prediction model in order to better understand the nature of the connection among conflicted teacher-child relationship, negative valence of peer interactive play, and maternal interpersonal relation satisfaction.

\section{Contributions and Limitations}

This study may contribute in understanding and improving the peer interaction problems by children and for developing programs in the educational field via diverse educational applications (e.g., relationship empowerment program, teacher education, effective parenting, and social competence enhancement program). This study suggests practitioners and teachers to include multiple informants in dealing with children who have relational problems in order to better understand the children and to come up with a variety of solutions for classroom conflict. Parents as well as children may gain benefits from intervention through acquiring relationship improvement skills, alternative perspectives on children's behavior, and different ways to interact with their children. Researchers may have directions of future studies from the current study. For future studies, it is suggested to investigate behavioral characteristics producing conflicted relationships with teachers and with peers in order to resolve maladaptive problems caused by children's conflicted interpersonal relationships in early childhood education institutes. Furthermore, the results of present study suggest that it is more efficient to include maternal interpersonal characteristics in implementing intervention programs for children who have conflicted or maladaptive peer relationship.

The present study has the following limitations. First, there may be some bias from single resource about dyadic relationships (i.e., teacher perceived teacher-child relationship and child-peer interaction). Addition of multi-informant and multi-assessment to the developmental research would be desirable design increasing reliability of the findings (e.g., direct observation for peer interaction) (see Vaughn, Shin, Kim, Coppola, Krzysik, Santos, Peceguina, Daniel, Veríssimo, DeVries, Elphick, Ballentina, Bost, Newell, Miller, Snider, \& Korth, 2009; Kim, Goetz, Moorer, \& Vaughn, 2009). It is valuable since researchers, by doing this, are able to solve the problems caused by shared-rater variance and portray a holistic child across different contexts. In order to examine multiple perspectives from participants, person-centered approach rather than variable-centered would fit better with relationship and interaction research letting us better understand the developmental processes. Secondly, the current study was challenged in terms of controlling factors that potentially impact on the results. For example, the intrinsic characteristics of 
children and significant personnel surrounding the children (e.g., temperament, attachment types, education, teaching or childrearing history, physical and mental health) may play a role to change the results beyond the major impact by the conflicted teacher-child relationship on children's peer interaction quality.

\section{Acknowledgements}

This work was supported by the National Research Foundation of Korean Government (NRF-2011-330-B00168).

\section{References}

Baker, J. A. (2006). Contributions of teacher-child relationships to positive school adjustment during elementary school. Journal of School Psychology, 44(3), 211-229.

Berndt, T. J., \& Hoyle, S. G. (1985). Stability and change in childhood and adolescent friendships. Developmental Psychology, 21, 10071015.

Birch, S. H. (2001). Children's relationships with peers and teachers: Assessment, linkages between relationship systems, and associations with school adjustment. Unpublished doctoral dissertation, University of Illinois, Urbana-Champaign.

Birch, S. H., \& Ladd, G. W. (1996a, April). Continuity and change in the quality of teacher-child relationships: Links with children's early school adjustment. In S. H. Birch (Chair), Children's relationships with teachers: Assessment, continuity, and linkages with school adjustment. Symposium conducted at the Annual Meeting of the American Educational Research Association, New York, NY.

Birch, S. H., \& Ladd, G. W. (1997). The teacher-child relationship and children's early school adjustment. Journal of School Psychology, 35(1), 61-79.

Bronfenbrenner, U. (1979). Contexts of child rearing: Problems and prospects. American Psychologist, 34, 844-850.

Cassidy, J., \& Asher, S. R. (1992). Loneliness and peer relations in young children. Child Development, 63, 350-365.

Choi, Y. -H. (1995). A study on the predictability of the maternal attitude from preschooler's temperament and mother's mental stability. Journal of the Korean Home Economics Association, 33, 187-196.
Coie, J. D., \& Dodge, K. A. (1983). Continuities and change in children's sociometric status: A five-year longitudinal study. MerrillPalmer Quarterly, 29, 261-282.

Coie, J. D., Dodge, K. A., \& Kupersmidt, J. (1990). Peer group behavior and social status. In S. R. Asher, \& J. D. Coie (Eds.), Peer rejection in childhood, (pp. 178-201). New York, NY: Cambridge University Press.

Cook, W. L. (2001). Interpersonal Influence in Family Systems: A social relations model analysis. Child Development, 72, 1179-1197.

Cook, W. L. (1994). A structural equation model of dyadic relationships within the family system. Journal of Consulting and Clinical Psychology, 62, 500-509.

Cook, W. L., Kenny, D. A., \& Goldstein, M. J. (1991). Parental affective style risk and the family system: A social relations model analysis. Journal of Abnormal Psychology, 100, 492-501.

Crockenberg, S., \& Litman, C. (1990). Autonomy as competence in 2-year-olds: Maternal correlates of child defiance, compliance, and self-assertion. Developmental Psychology, 26, 961-971.

Davies, P. T., \& Cummings, E. M. (1994). Marital conflict and child adjustment: An emotional security hypotheses. Psychological Bulletin, 116, 387-411.

Dishion, T. J., Patterson, G. R., Stoolmiller, M., \& Skinner, M. L. (1991). Family, school, behavioral antecedents to early adolescents involvement with antisocial peers. Developmental Psychology, 27, 172-180.

Ewing, A. R., \& Taylor, A. R. (2009). The role of child gender and ethnicity in teacher-child relationship quality and children's behavioral adjustment in preschool. Early Childhood Research Quarterly, 24(1), 92-105.

Fantuzzo, J. W., Sutton-Smith, B., Coolahan, K. C., Manz, P., Canning, S., \& Debnam, D. (1995). Assessment of play interaction behaviors in young low-income children: Penn Interactive Peer Play Scale. Early Childhood Research Quarterly, 10, 105-120.

George, C., \& Main, M. (1979). Social interactions of young abused children: Approach, avoidance, and aggression. Child Development, 50, 306-318

Hwang, Y. -M., \& Moon, H. -J. (2010). The effects of young children and their mother's variables on peer acceptance of the children. Journal of the Korean Home Economics Association, 48, 17-30.

Howes, C., \& Phillipsen, L. (1996, April). The consistency and predictability of teacher-child relationships during the transition to 
kindergarten. In S. H. Birch (Chair), Children's relationships with teachers: Assessment, continuity, and linkages with school adjustment. Symposium conducted at the Annual Meeting of the American Educational Research Association, New York, NY.

Kim, M. (2010). Conflict and harmony during interaction of preschool children: Influences of relationship status of dyads. Unpublished doctoral dissertation, Auburn University, Auburn.

Kim, M., Goetz, S., Moorer, A., \& Vaughn, B. E. (2009). Conflict and harmony during interactions of preschool children: Influences of age, sex, and relationship status. Poster presentation at biannual meeting of Society of Research in Child Development, Denver, CO.

Kim, G. -H., \& Lee, J. -M. (2011). A study on the structure model of parental role satisfaction and marital satisfaction on the relationship between mothers' parenting efficacy and life satisfaction. Korean Journal of Child Welfare, 9, 19-38.

Ladd, G. W., Birch, S. H., \& Bubs, E. S. (1999). Children's social and scholastic lives in kindergarten: Related spheres of influence? Child Development, 70, 1373-1400.

Lamborn, S. D., Mounts, N. S., Steinberg, L. , \& Dornbusch, S. M. (1991). Patterns of competence and adjustment among adolescents from authoirative, authoritarian, indulgent, and neglectful families. Child Development, 62, 1049-1065.

Lee, J. (2001). An association among attachment representation, teacher-child relationship, social competence of preschool children. Unpublished doctoral dissertation, KyungHee University, Seoul, Korea.

Leech, N. L., Barrett, K. C., Morgan, G. A. (2008). SPSS for intermediate statistics: Use and interpretation (3rd ed.). New York: Lawrence Erlbaum Associates.

Macdonald, K., \& Parke, R. D. (1984). Bridging the gap: Parent-child play interaction and peer interactive competence. Child Development, $55,1265-1277$.

Miller, J. B. (1993). Learning from early relationship experience. In S. Duck (Ed.), Learning about relationships (pp. 1-29). London: Sage Publications.

O'Conner, E., \& McCartney, K. (2007). Examining teacherchild relationship and achievement as part of ecological model of development. American Educational Research Journal, 44, 340-369.

Ladd, G. W. (1992). Themes and theories: Perspectives on processes in family-peer relationships. In R. D. Parker \& G. W. Ladd (Eds.), Family-peer relationship: Modes of linkage (pp. 1-34). Hillsdale, NJ: Lawrence Erlbaum Associates.

Pianta, R. C. (1999). Enhancing relationships between children and teachers. Washington, DC: American Psychological Association.

Pianta, R. C. (2001). Student-teacher relationship scale. Lutz, FL: Psychological Assessment Resources, Inc.

Putallaz, M., \& Heflin, A. H. (1990). Parent-child interaction. In S. R. Asher \& J. D. Coie (Eds.), Peer rejection in childhood, 6. New York: Cambridge University Press.

Rubin, K. H., Bukowski, W., \& Parker, J. G. (2006). Peer interactions, relationships, and groups. In W. Damon (Series Ed.) \& N. Eisenberg (Vol. Ed.), Handbook of child psychology: Vol1. Theoretical models of human development; Vol 3. Social-emotional and personality development (5th ed., pp. 619-700). New York: Wiley.

Sheldon, A. (1992). Conflict talk: Sociolinguistic challenges to selfassertion and how young girls meet them. Merrill-Palmer Quarterly, 38, 95-117.

Strand, P. S., \& Wahler, R. G. (1996). Predicting maladaptive parenting: Role of maternal object relations. Journal of Clinical Child Psychology, 43-51.

Vaughn, B. E., Shin, N., Kim, M., Coppola, G., Krzysik, L., Santos, A. J., Peceguina, I., Daniel, J. R., Veríssimo, M., DeVries, A., Elphick, E., Ballentina, X., Bost, K. K., Newell, W. Y., Miller, E. B., Snider, J. B., \& Korth, B. (2009). Hierarchical models of social competence in preschool children: A multi-site, multi-national study. Child Development, 80, 1775-1796.

Wahler, R. G., \& Dumas, J. E. (1986). Maintenance factors in coercive mother-child interactions: An interbehavioral model. Psychological Bulletin, 105, 116-130.

Yoon, M. -S., \& Kim, S. -H. (2012). Mediating effect of relationship satisfaction on the relationship between traumatic experiences and suicidal ideation among college students. Mental Health and Social Work, 40, 5-32. 